\title{
PENINGKATAN CUSTOMER VALUE PRODUK OLAHAN SAYUR ORGANIK DI DESA CIBODAS KECAMATAN LEMBANG KABUPATEN BANDUNG BARAT
}

\author{
Rani Andriani Budi Kusumo, Anne Charina, dan Yayat Sukayat \\ Departemen Sosial Ekonomi Pertanian Fakultas Pertanian Universitas Padjadjaran \\ E-mail : raniandriani081@gmail.com
}

\begin{abstract}
ABSTRAK. Desa Cibodas saat ini selain menjadi desa penghasil produk hortikultura juga berkembang menjadi desa pariwisata yang potensial. Kelompok Tani Mekar Tani Jaya sebagai salah satu kelompok penghasil sayuran di Desa Cibodas menangkap ini sebagai peluang potensial untuk meningkatkan nilai tambah dari produk sayuran yang mereka hasilkan dengan mengolah produk olahan sayuran organik. Kegiatan Pengabdian Kepada Masyarakat ini bertujuan agar mitra dapat menghasilkan produk dengan kemasan dan atribut uang layak jual (diantaranya mendaftarkan produknya untuk memperoleh Sertifikasi PIRT). Metode pelaksanaan dari kegiatan ini adalah : 1) Penyuluhan mengenai cara meningkatkan nilai tambah produk melalui kemasan yang baik dan menarik; 2) Penyuluhan mengenai pentingnya sertifikasi PIRT; 3) Pemberian bantuan alat; 4) Pendampingan pada mitra. Setelah diberikan materi, sebagian besar peserta memiliki tambahan pengetahuan bahwa produk yang mereka hasilkan dapat ditingkatkan nilai jualnya melalui teknis pengemasan yang baik dan menarik serta pentingnya sertifikat PIRT sebagai salah satu jaminan legalitas produk bagi konsumen. Dari sisi keterampilan, sebagian besar pelatihan telah mampu untuk memilih kemasan yang baik sesuai fungsinya serta mampu untuk mempraktekkan langkah-langkah untuk memperoleh sertifikat PIRT.
\end{abstract}

Kata kunci: customer value; olahan; organic; sayuran.

\section{INCREASING CUSTOMER VALUE OF ORGANIC VEGETABLE PROCESSED PRODUCTS IN DESA CIBODAS KECAMATAN LEMBANG KABUPATEN BANDUNG BARAT}

\begin{abstract}
Cibodas village besides being a village producing horticultural products also develops into a potential tourism village. Mekar Tani Jaya Farmers Group as one of the vegetable producing groups in Cibodas Village captures this as a potential opportunity to increase the added value of vegetable products they produce by processing organic vegetable processed products. This activity aims to enable partners to produce products with packaging and attributes for sale(including registering their products to obtain PIRT Certification). The implementation methods of this activity are: 1) Counseling on how to increase the added value of products through good and attractive packaging; 2) Counseling on the importance of PIRT certification; 3) Provision of equipment assistance; 4) Assistance to partners. After being given training, most participants have additional knowledge that the products they produce can be increased in value through good and attractive packaging techniques and the importance of PIRT certificates as a guarantee of product legality for consumers. In terms of skills, most of the participants has been able to choose good packaging according to its function and able to practice the steps to obtain a PIRT certificate.
\end{abstract}

Key words: customer value; processed; organic; vegetables.

\section{PENDAHULUAN}

Kesadaran masyarakat akan pentingnya kesehatan dan pergeseran gaya hidup sehat dan ramah lingkungan menjadi tantangan tersendiri bagi dunia pertanian. Pola hidup sehat yang ramah lingkungan telah melembaga secara internasional yang mensyaratkan jaminan bahwa produk pertanian harus aman dikonsumsi, memiliki kandungan nutrisi yang tinggi dan ramah lingkungan (Mayrowani, 2012). Untuk itu petani sebagai produsen dituntut untuk menjalankan pertanian berkelanjutan yang lebih memperhatikan aspek lingkungan. Sistem pertanian organic merupakan implementasi dari sistem pertanian berkelanjutan. Sutanto (2002) menjelaskan pelaksanaan pertanian berkelanjutan adalah dengan membatasi ketergantungan pada pupuk anorganik dan bahan kimia pertanian lainnya, dengan tujuan agar praktek pertanian tidak menimbulkan kerusakan alam.

Pemerintah mendukung perkembangan pertanian organik dengan meluncurkan program 'Go Organik 2010'. Program tersebut bertujuan untuk mempercepat terwujudnya agribisnis berwawasan lingkungan guna meningkatkan kesejahteraan masyarakat khusus nya petani. Setelah program Go Organik pemerintah kembali mencanangkan program 1000 Desa Organik dengan sasaran 600 Desa Organik Pangan, 250 Desa Organik Hortikultura dan 150 Desa Organik Perkebunan. Desa Cibodas termasuk ke dalam salah satu desa yang terpilih sebagai Desa Organik Hortikultura. Pengembangan desa organik ini bertujuan mengubah perilaku mayarakat dari hulu sampai hilir dengan menerapkan aktifitas non kimiawi dalam usaha tani nya.

Program Desa Organik di Desa Cibodas mendorong petani untuk menjalankan usahatani hortikultura sesuai dengan prinsip ramah lingkungan. Seiring perkembangannya, Desa Cibodas saat ini selain menjadi desa penghasil produk hortikultura juga berkembang menjadi desa pariwisata yang potensial semenjak adanya tempat wisata Lodge of Maribaya. Salah satu usaha untuk meningkatkan minat masyarakat yang bergerak di sektor pertanian dan menciptakan hasil yang optimal adalah dengan menggerakan sektor usaha potensial daerah 
tersebut. Oleh karenanya diperlukan wirausaha-wirausaha yang mampu mengali potensi daerah setempat (Rochdiani et al, 2018).

Para petani mulai mendapatkan benefit sampingan dengan menyediakan jasa "home stay" rumah mereka untuk wisatawan baik domestic maupun asing. Selain itu seiring dengan berkembangnya usaha homestay dan pariwisata, banyak wisatawan yang mencari penganan dan oleh oleh khas dari Desa Cibodas. Kelompok Tani Mekar Tani Jaya sebagai salah satu kelompok penghasil sayuran di Desa Cibodas menangkap ini sebagai peluang potensial untuk meningkatkan nilai tambah dari produk sayuran yang mereka hasilkan. Mereka berniat untuk merambah bisnis baru yaitu olahan dari sayur organic.

Permasalahan yang dihadapi mitra adalah: mereka belum memiliki pengetahuan dan keterampilan dalam bisnis olahan sayur organic yang baik yang bisa dipasarkan sebagai oleh-oleh, yang memiliki standar mutu serta kemasan yang layak pasar. Pada tahun pertama kegiatan PPM dilaksanan untuk memberikan keterampilan pada mitra mengenai pembuatan produk olahan dari sayuran organik. Pada tahun kedua ini kegiatan PPM ditujukan untuk meningkatkan customer value dari usaha pengolahan sayur organic yang sudah mulai dijalankan oleh mitra. Hasil penelitian Pramudita dan Japarianto (2013) menjelaskan bahwa variabel customer value berpengaruh signifikan terhadap kepuasan konsumen, lebih lanjut Effendi dan Kunto (2013) menunjukkan customer value akan mempengaruhi minat beli konsumen. Melalui kegiatan PPM ini diharapkan permintaan konsumen akan produk olahan sayuran organic di Desa Cibodas dapat meningkat, yang pada akhirnya akan meningkatkan pendapatan keluarga petani.

\section{METODE}

Luaran yang diharapkan dari kegiatan ini adalah mitra dapat menghasilkan produk dengan kemasan dan atribut yang layak jual (diantaranya mendaftarkan produknya untuk memperoleh Sertifikasi PIRT). Kegiatan ini diharapkan dapat menjadikan Desa Cibodas menjadi pelopor Desa Organik yang terintegrasi dari hulu-hilir. Adapun metode pelaksanaan dari kegiatan ini adalah sebagai berikut.

1. Penyuluhan mengenai cara meningkatkan nilai tambah produk melalui kemasan yang baik dan menarik

2. Penyuluhan mengenai pentingnya sertifikasi PIRT

3. Pemberian bantuan alat

4. Pendampingan pada mitra

Pelaksanaan kegiatan lebih banyak dilakukan dengan cara pelatihan atau workshop sehingga mitra dapat langsung melaksanakan praktek sehingga peserta dapat lebih mudah untuk menguasai materi yang diberikan. Ife dan tesoriero (2008) menjelaskan bahwa pelatihan berperan dalam meningkatkan keterampilan tertentu yang dibutuhkan oleh masyarakat untuk meningkatkan kualitas hidupnya. Dalam konteks pemberdayaan masyarakat, agar masyarakat dapat mandiri tentunya tidak serta merta hanya membuat suatu pelatihan saja, tetapi perlu adanya tindak lanjut yang berkesinambungan setelah pelatihan diberikan. Tindak lanjut akan berjalan lebih efektif jika adanya suatu pendampingan yang berkelanjutan (Saugi \& Sumarno, 2015). Secara rinci tahapan kegiatan PPM beserta keterlibatan berbagai pihak dalam kegiatan PPM, dapat dilihat pada Tabel 1 berikut.

Tabel 1. Tahapan Kegiatan Pengabdian Kepada Masyarakat

\begin{tabular}{|c|c|c|c|c|}
\hline \multirow{2}{*}{ No } & \multirow{2}{*}{ Kegiatan } & \multicolumn{3}{|c|}{ Keterlibatan dalam kegiatan } \\
\hline & & Dosen & Mahasiswa & Masyarakat \\
\hline \multirow[t]{4}{*}{1.} & Persiapan & & & \\
\hline & Identifikasi Masalah & $\begin{array}{l}\text { Dosen melakukan kegiatan FGD } \\
\text { bersama mitra untuk mengidentifikasi } \\
\text { masalah apa yg dihadapi oleh } \\
\text { kelompok sasaran }\end{array}$ & & $\begin{array}{l}\text { Mitramemberikan informasi } \\
\text { mengenai masalah yang dihadapi } \\
\text { serta potensi yang dimiliki. }\end{array}$ \\
\hline & Penyiapan Alat Bahan & $\begin{array}{l}\text { Dosen menyiapkan alat dan bahan } \\
\text { yang diperlukan untuk kegiatan PPM }\end{array}$ & $\begin{array}{l}\text { Mahasiswa membantu } \\
\text { menyiapkan alat bahan sesuai } \\
\text { dengan instruksi dosen }\end{array}$ & $\begin{array}{l}\text { Masyarakat membantu } \\
\text { menyiapkan alat bahan yang } \\
\text { tersedia di lokasi PPM }\end{array}$ \\
\hline & Sosialisasi & $\begin{array}{l}\text { Dosen melakukan kegiatan sosialisasi } \\
\text { program kepada masyarakat }\end{array}$ & $\begin{array}{l}\text { Mahasiswa membantu dosen ikut } \\
\text { Mensosialisasikan Kegiatan PPM } \\
\text { ini kepada Masyarakat }\end{array}$ & $\begin{array}{l}\text { Aparat Desa Mensosialisasikan } \\
\text { Kegiatan PPM ini kepada } \\
\text { Masyarakat }\end{array}$ \\
\hline \multirow[t]{5}{*}{2} & Pelaksanaan Program & & & \\
\hline & $\begin{array}{l}\text { Pelatihan 1: } \\
\text { Pelatihan pembuatan } \\
\text { kemasan yang baik dan } \\
\text { menarik }\end{array}$ & $\begin{array}{l}\text { Dosen memberikan pelatihan teoritis } \\
\text { mengenai kemasan yang baik dan } \\
\text { menarik }\end{array}$ & $\begin{array}{l}\text { Mahasiswa membantu dosen } \\
\text { dalam hal teknis pelaksanaan } \\
\text { pelatihan }\end{array}$ & $\begin{array}{l}\text { Masyarakat/mitra terlibat aktif } \\
\text { dalam pelatihan }\end{array}$ \\
\hline & $\begin{array}{l}\text { Pelatihan } 2 \text { : Pelatihan } \\
\text { pentingnya sertifikat } \\
\text { PIRT }\end{array}$ & $\begin{array}{l}\text { Dosen memberikan pelatihan secara } \\
\text { teoritis dan melakukan kegiatan } \\
\text { pendampingan pada kelompok sasaran }\end{array}$ & $\begin{array}{l}\text { Mahasiswa membantu dosen } \\
\text { dalam hal teknis pelaksanaan } \\
\text { pelatihan }\end{array}$ & $\begin{array}{l}\text { Masyarakat/mitra terlibat aktif } \\
\text { dalam pelatihan }\end{array}$ \\
\hline & $\begin{array}{l}\text { Pemberian bantuan alat } \\
\text { produksi }\end{array}$ & $\begin{array}{l}\text { Melakukan identifikasi alat-alat yang } \\
\text { diperlukan oleh mitra }\end{array}$ & & \\
\hline & Pendampingan & $\begin{array}{l}\text { Dosen mengidentifikasi sampai tahap } \\
\text { mana mitra membutuhkan pendampingan }\end{array}$ & & $\begin{array}{l}\text { Masyarakat/mitra terlibat aktif } \\
\text { dalam semua tahapan kegiatan }\end{array}$ \\
\hline
\end{tabular}




\section{HASIL DAN PEMBAHASAN}

Program kegiatan pengabdikan kepada masyarakat diawali dengan koordinasi dengan ketua kelompok tani Mekar Tani Jaya (MTJ) dan aparat Desa Cibodas Kecamatan Lembang yang merupakan salah satu lokasi kegitatan penelitian Riset Fundamental Unpad (RFU). Koordinasi awal dilakukan untuk menggali permasalahan yang dihadapi masyarakat dan alternative solusinya melalui kegiatan PPM. Selanjutnya koordinasi dilakukan untuk menentukan waktu pelaksanaan kegiatan PPM. Peserta kegiatan PPM ini adalah anggota PKK Desa Cibodas dan anggota kelompok tani MTJ Kecamatan Lembang sejumlah 30 orang. Pelaksaaan PPM juga terintegrasi dengan kegiatan KKN mahasiswa dan mahasiswa terlibat aktif dalam kegiatan PPM yang dilaksanakan.

Penyampaian materi dilakukan di sekretariat kelompok tani MTJ. Modul digunakan sebagai alat bantu penyampaian materi. Selain itu peserta juga diajak untuk mempraktekkan bagaimana mengemas produk yang baik dan mendesain kemasan yang menarik. Kemasan selain berfungsi sebagai wadah atau tempat yang membungkus atau melindungi produk juga dapat berfungsi sebagai media promosi bagi produk yang dikemas. Oleh karena itu, disain kemasan perlu dibuat semenarik mungkin, baik dari material kemasan maupun dari segi grafis (Rosalina et al,2011). Denison (1999) menyebutkan pada saat mendisain kemasan tidak ada yang benar dan yang salah, tetapi yang layak dan tidak layak menurut konsumen yang dituju. Selain dalam hal kemasan, consumer value juga dapat ditingkatkan melalui sertifikasi produk diantaranya adalah sertifikat PIRT sebagai jaminan legalitas produk yang dihasilkan.

Setelah mengikuti serangkaian kegiatan, perubahan pengetahuan dan keterampilan peserta dapat dijelaskan pada Tabel 2 di bawah ini.
Hasil dari rangkaian kegiatan PPM yang telah dilaksanakan, dapat dijabarkan sebagai berikut :

1. Tingkat Partisipasi Peserta

Kegiatan pelatihan dilaksanakan dilaksanakan di kantor sekretariat kelompok tani MTJ Desa Cibodas Kecamatan Lembang. Lokasi tersebut dipilih berdasarkan pertimbangan

- Mudah dijangkau oleh peserta

- Fasilitas yang terdapat di lokasi sangat menunjang kegiatan ceramah dan praktek peningkatan nilai jual produk olahan sayuran organik

Kriteria tersebut menjadi dasar bagi tim PPM setelah melalui diskusi dengan aparat Desa Cibodas. Hampir seluruh peserta hadir dalam kegiatan pelatihan.

2.Perubahan Pengetahuan dan Keterampilan Peserta Hasil yang dicapai adalah terjadinya peningkatan pengetahuan dan keterampilan peserta, yang diketahui berdasarkan hasil pre test dan post test. Pada awalnya, sebagian besar peserta belum pernah mengikuti pelatihan sejenis dan belum memiliki pengetahuan bagaimana meningkatkan nilai jual produk olahan sayuran organic melalui pembuatan kemasan yang baik dan menarik sehingga dapat menjadi komoditas unggulan di desa mereka.

Setelah diberikan materi, sebagian besar peserta memiliki tambahan pengetahuan bahwa produk yang mereka hasilkan dapat ditingkatkan nilai jualnya melalui teknis pengemasan yang baik dan menarik serta pentingnya sertifikat PIRT sebagai salah satu jaminan legalitas produk bagi konsumen. Dari sisi keterampilan, sebagian besar pelatihan telah mampu untuk memilih kemasan yang baik sesuai fungsinya serta mampu untuk mempraktekkan langkah-langkah untuk memperoleh sertifikat PIRT.

\section{Tabel 2. Hasil Pelaksanaan Kegiatan Peningkatan Customer Value Produk Olahan Sayuran Organik}

\begin{tabular}{|c|c|c|}
\hline No. & Program & Hasil Kegiatan \\
\hline 1 & Sosialisasi & $\begin{array}{l}\text { - Sosialisasi Dilakukan melalui penyampaian maksud dan tujuan kegiatan secara langsung pada apparat } \\
\text { Desa Cibodas dan kelompok tani MTJ }\end{array}$ \\
\hline 2 & Identifikasi Masalah & - Permasalahan didapat dari hasil penelitian hibah RFU dan juga diskusi dengan aparat Desa Cibodas \\
\hline 3 & Identifikasi Materi & $\begin{array}{l}\text { - Tersusun materi yang sesuai bagi kebutuhan mitra dan penyelesaian masalah yang dihadapi mitra yaitu } \\
\text { khususnya mengenai pengemasan dan pemasaran produk olahan sayuran organic }\end{array}$ \\
\hline 4 & Identifikasi Peserta & - Terdaftar calon peserta pelatihan yaitu anggota PKK Desa Cibodas dan anggota kelompok tani MTJ \\
\hline 5 & Identifikasi Pemateri & - Pemateri adalah staf pengajar dari Prodi Agribisnis serta praktisi di bidang pengemasa \\
\hline 6 & Penyiapan Alat Bahan & - Tersedia alat dan bahan penunjang efektivitas pelatihan partisipatif \\
\hline 7 & Identifikasi Lokasi & - Lokasi kegiatan dilaksanakan di secretariat kelompok tani MTJ \\
\hline 8 & $\begin{array}{l}\text { Pelatihan } 1 \text { : Pelatihan } \\
\text { pembuatan kemasan } \\
\text { yang baik dan } \\
\text { menarik }\end{array}$ & $\begin{array}{l}\text { - Tingkat partisipasi masyarakat dalam pelatihan sangat baik, hampir seluruh peserta yang diundang } \\
\text { datang } \\
\text { - Peserta sangat antusias karena mendapat tambahan informasi dan pengetahuan kognitif sekitar } 95 \% \text {. } \\
\text { - Terjadi peningkatan keterampilan pada peserta sebesar kurang lebih } 90 \% \text { dalam memilih kemasan yang } \\
\text { baik dan mendesain kemasan yang menarik }\end{array}$ \\
\hline 9 & $\begin{array}{l}\text { Pelatihan } 2 \text { : Pelatihan } \\
\text { pentingnya sertifikat } \\
\text { PIRT }\end{array}$ & $\begin{array}{l}\text { - Tingkat partisipasi masyarakat dalam pelatihan sangat baik, hampir seluruh peserta yang diundang } \\
\text { datang } \\
\text { - Pengetahuan peserta mengenai pentingnya sertifikat PIRT dan langkah untuk memperoleh sertifikat PIRT } \\
\text { meningkat sebanyak } 95 \%\end{array}$ \\
\hline 10 & Pemberian bantuan alat & - Tersedianya alat produksi produk olahan sayuran organic, seperti kompor, penggiling mie dan sealer \\
\hline
\end{tabular}




\section{Penambahan alat penunjang produksi}

Selain memberikan pelatihan yang bertujuan untuk meningkatkan pengetahuan dan keterampilan peserta, tim PPM juga memberikan bantuan alat produksi berupa kompor gas, mesin penggiling mie dan sealer kepada tiga kelompok usaha produk olahan sayuran organic yang dinilai potensial untuk berkembang. Tujuan dari pemberian bantuan alat ini adalah untuk mendorong peserta (kelompok usaha) agar mampu menghasilkan produk yang berkualitas dan layak jual.

4. Perluasan pasar produk olahan sayuran organik Pada awalnya, sebagian besar peserta membuat produk olahan sayuran organik sekedar untuk dijadikan suguhan ataupun dijual sebagai oleh-oleh pada tamu homestay. Mereka belum memasarkan secara lebih luas dikarenakan mereka menginginkan produknya dikemas agar lebih menarik konsumen. Setelah mengikuti pelatihan, peserta mulai mencoba memasarkan produknya kepada wisatawan yang datang ke Desa Cibodas dengan cara menitipkannya di tempat-tempat wisata yang ada di sekitar Desa Cibodas. Ada beberapa peserta yang juga mulai menawarkan paket wisata edukasi di bidang pertanian kepada wisatawan dimulai dengan kunjungan ke kebun petani dan diakhiri dengan membuat produk olahan sayuran organic.

Dalam memberikan materi kepada peserta, metode pembelajaran dan alat bantu pembelajaran menjadi bagian penting untuk mencapai tujuan kegiatan yang telah ditetapkan. Evaluasi mengenai metode dan alat bantu pembelajaran yang diterapkan dapat dijabarkan sebagai berikut :

1. Metode Pembelajaran

Metode pembelajaran dilaksanakan secara partisipatif mulai dari awal sampai akhir kegiatan. Pembelajaran diawali dengan kegiatan ceramah mengenai peningkatan nilai jual dari produk olahan sayuran organic, pentingnya sertifikat PIRT serta peluang usaha produk olahan sayuran organik.

2. Metode Fasilitasi

Metode fasilitasi tentu saja melibatkan masyarakat, dimana dengan adanya kegiatan PPM ini berusaha mempertemukan antara praktisi, aparat desa yang terkait dengan anggota PKK. Melalui kegiatan ini, diperoleh hasil bahwa kepala Desa Cibodas akan memfasilitasi kegiatan pemasaran bekerjasama dengan beberapa tempat wisata yang ada di Desa Cibodas.

3. Materi dan alat bantu Pembelajaran

Materi pembelajaran diberikan sesuai dengan kebutuhan peserta dan disampaikan melalui modul yang disajikan dalam bahasa yang mudah dipahami dan ringkas padat. Alat bantu sudah terintegrasi, langsung, juga dengan menggunakan audio visual dan praktik.

\section{SIMPULAN}

Kegiatan PPM ini dilaksanakan sebagai upaya meningkatkan nilai tambah dan nilai jual produk olahan sayuran organik. Hasil kegiatan menunjukkan perubahan pengetahuan dan keterampilan peserta. Peserta menjadi paham pentingnya kemasan dan pembuatan sertifikat PIRT untuk meningkatkan nilai jual produk.

\section{UCAPAN TERIMA KASIH}

Terima kasih kepada Universitas Padjadjaran yang telah memfasilitasi kegiatan pengabdian kepada masyarakat ini melalui skema Hibah Internal Unpad tahun anggaran 2018.

\section{DAFTAR PUSTAKA}

Denison, E., Cawthray, R. (1999). Packaging Prototypes: Design Fundamentals. Switzerland: Rotovision.

Effendi, A.Y., Kunto, Y,S. (2013). Pengaruh Customer Value Proposition Terhadap Minat Beli Konsumen Pada Produk Consumer Pack Premium Baru Bogasari. Jurnal Manajemen Pemasaran PETRA, $1(2): 1-8$.

Ife, J. \& Tesoriero, F. (2008). Community Development: Alternatif Pengembangan Masyarakat Di Era Globalisasi. Yogyakarta: Pustaka Pelajar

Mayrowani, H. (2012). Pengembangan Pertanian Organik di Indonesia. Forum Penelitian Agro Ekonomi, 30, (2) : 91-108.

Pramudita, Y.A., Japarianto, E. (2013). Analisa Pengaruh Customer Value dan Customer Experience terhadap Customer Satisfaction di De Kasteel Resto Surabaya. Jurnal Manajemen Pemasaran PETRA, 1, (1) : 1-7.

Rochdiani, D., Kusumo, R.A.B., Wiyono, S.N., Qanti, S.R., Sadeli, A.H. (2018). Manajemen Usaha Home Industry Desa Sindangsari Kecamatan Sukasari Kabupaten Sumedang. Jurnal Dharmakarya, 7, (1): $51-55$

Rosalina, Y., Alnopri., Prasetyo. (2011). Disain Kemasan Untuk Meningkatkan Nilai Tambah Madu Bunga Kopi Sebagai Produk Unggulan Daerah. Jurnal Agroindustri, 2, (1) : 8-13.

Saugi, W., Sumarno. (2015). Pemberdayaan Perempuan Melalui Pelatihan Pengolahan Bahan Pangan Lokal. Jurnal Pendidikan dan Pemberdayaan Masyarakat, 2, (2) : 226-238.

Sutanto, R. 2002. Pertanian Organik: Menuju Pertanian Alteratif dan Berkelanjutan. Yogyakarta: Penerbit Kanisius. 